\title{
"Teachers are not empty vessels": A Reception Study of Freeman and Johnson's (1998) Reconceptualization of the Knowledge Base of Second Language Teacher Education
}

\author{
Joseph J. Lee, John Murphy, E Amanda Baker
}

This study traces the reception history of Freeman and Johnson's (1998) widely cited article dedicated to theory and practices of second language teacher education (SLTE). It illuminates the degree to which that article has impacted SLTE theory, research, and potentially instructional practices. The reception study analysis is based on a data set of 413 journal articles, books, book chapters, master's theses, and doctoral dissertations that cited Freeman and Johnson (FEJ) between 1999 and 2014. Using an innovative analytical approach combining both Hyland's $(1999,2004)$ citation categories and Coffin's (2009) stance framework, we investigate the citation analytics of FEJ within this data set, including how it has been cited over time and the stance that citing authors have taken toward FEJ's proposals. Although FEJ's reconceptualization of the theory and practices of SLTE sparked initial controversy, our findings indicate that FEJ's article has not only been accumulating increased attention over time, but their vision for the future of SLTE also has gained greater acceptance and has edged closer to the center of SLTE. The article concludes with a discussion of implications for further reception studies in TESOL/applied linguistics.

Cette étude trace le parcours de l'histoire de la réception de article, largement cité, de Freeman et Johnson (1998) portant sur la théorie et les pratiques en formation des enseignants de langue seconde. Elle souligne la mesure dans laquelle l'article a eu un impact sur la théorie, la recherche, voire les pratiques pédagogiques, en formation des enseignants de langue seconde. L'analyse de la réception de l'article repose sur un ensemble de données composé de 413 articles de revue, livres, chapitres de livre, et thèses de maitrise et de doctorat qui citent Freeman et Johnson (FEJ) entre 1999 et 2014. Adoptant une approche analytique innovatrice qui combine les catégories de citation de Hyland (1999, 2004) et le cadre des positions de Coffin (2009), nous examinons les citations de FEJ, y compris la façon dont l'article est cité au fil du temps et la position des auteurs qui le citent par rapport aux propositions de FEJ. Bien que la reconceptualisation par FEJ de la théorie et des pratiques en formation des enseignants de langue seconde ait d'abord suscité une controverse, nos résultats indiquent 
qu'avec le temps, l'article attire de plus en plus d'attention et que la vision que proposent FEJ de l'avenir de la formation des enseignants de langue seconde est mieux reçue et prend davantage sa place dans le domaine. L'article se termine par une discussion des incidences des études portant sur la réception d'articles en linguistique appliquée/TESOL à l'avenir.

Pivotal moments in a discipline's history fundamentally revolutionize both its core knowledge base and its future research trajectories. In the field of second language teacher education (SLTE), the publication of Freeman and Johnson's widely cited article, "Reconceptualizing the Knowledge-Base of Language Teacher Education" (1998), is considered one such moment. This cornerstone article is believed to have had a powerful impact on SLTE theory, research, and practice among members of the SLTE community (Faez, 2011; Fleming, Bangou, \& Fellus, 2012; Salas, 2007), and those scholars and researchers directly involved in theorizing and researching issues related to SLTE. Freeman and Johnson (F\&J) proposed a different view of what constitutes the knowledge base of SLTE, departing from a historical view of a "binary distinction between subject matter and learners" that resulted in a transmission perspective of language education (p. 406). Core components of this new perspective include sources of teacher knowledge, processes of teacher learning, and ways of exploring teachers' understandings of their classroom practice, ultimately encompassing sociocultural processes that underlie teacher learning. As more than 16 years have passed since its publication in 1998, an empirical investigation is needed into how a seminal work such as F\&J's reconceptualization paper has impacted the SLTE field, ultimately to better understand contemporary SLTE theories and practice.

Numerous narrative literature reviews exist on the work of F\&J and other significant contributions to SLTE (e.g., Vélez-Rendón, 2002; Wright, 2010), but these types of syntheses are not designed to deal with how any particular article may have impacted the SLTE community in depth. Thus, this article examines F\&J's reception history by using an innovative, analytical approach combining both Hyland's (1999, 2004) citation categories and Coffin's (2009) stance framework. We investigate how F\&J's article has been cited and the stance citing authors have taken toward the proposed reconceptualization between 1998 and 2014, and propose several reasons for its scholarly success. We begin by highlighting key issues from F\&J's article and offering a brief overview of the field of reception studies.

\section{F\&J's (1998) reconceptualized SLTE Knowledge Base}

In their 1998 article dedicated to theory and practices of SLTE, F\&J raised several important issues regarding the nature of the knowledge base of SLTE, 
and proposed a new social constructivist framework. They leveled three major criticisms toward the established approach to SLTE:

1. Historically, the SLTE knowledge base has rested on decontextualized bodies of theoretical knowledge from traditional disciplines such as linguistics and second language acquisition (SLA).

2. Compartmentalized bodies of knowledge are delivered through a transmission model of instruction in discrete SLTE courses.

3. Traditional disciplines that have contributed to the SLTE knowledge base have a limited role and impact on second language (L2) teachers' work due to their disconnection from the activity and contexts of L2 teaching.

In response to this behaviourist, process-product approach to preparing L2 teachers, F\&J proposed a socially situated, interconnected, tripartite framework for the SLTE knowledge base that centres on the activity of teaching: teacher-as-learner, social context of school and schooling, and activity of teaching and learning. According to F\&J, "teachers are not empty vessels waiting to be filled with theoretical and pedagogical knowledge" (p. 401). Therefore, the first domain of teacher-as-learner focuses on the impact of L2 teachers' prior knowledge, beliefs, and experiences on pedagogical practices, and the complex variables that contribute to L2 teachers' learning to teach. F\&J also contend that SLTE "must be understood against the backdrop of teachers' professional lives" (p. 405). The second domain in the framework thus underscores the synchronic and diachronic influences that sociocultural contexts of schools and social processes of schooling have on pedagogical practices and on L2 teachers' learning-to-teach processes. Finally, the last domain centres on "[w] ho teaches what to whom, where?" (p. 405) - the activity of teaching itself, grounded in L2 teachers' understanding of language learners and learning processes, and the interconnectedness to teachers and learners, the classroom, and the school contexts in which teaching and learning occur.

In F\&J's view, the activity of L2 teaching itself should form the core of the SLTE knowledge base. This placement therefore shifts more traditional disciplines away from the core, but, in F\&J's estimation, they continue to inform the knowledge base from a more peripheral location. This proposal sparked initial controversy in the SLTE community. Several well-known debates ensued between F\&J $(2004,2005)$ and other specialists (Muchisky \& Yates, 2004; Tarone \& Allwright, 2005; Yates \& Muchisky, 2003); however, little is known of how the SLTE community as a whole received F\&J's proposals both prior to and following these debates. Conducting a reception study into the impact of F\&J's work may provide a fuller understanding of how and to what degree the field at large has been impacted by their conceptualization of the SLTE knowledge base. 


\section{Reception Studies}

Foundational theories, research, and practices of a discipline are identified primarily through publications. The contents of these publications and their authors' proposals are either accepted, contested, or neglected depending on community members' perceptions of the merits of the works in contributing to the knowledge base of the field. Such responses come in various forms. In academic journals, for example, these include forum discussions, focus issues, and references to citations. In forum discussions, readers directly react to a published article either positively or negatively within the same or subsequent issue (e.g., Yates \& Muchisky's 2003 response to F\&J), which is then occasionally followed by a response from the original article's author(s). In focus issues, a journal dedicates an issue to a focal article that appears along with commentaries, and sometimes with a reaction from the focal article's author(s) (e.g., Firth \& Wagner, 1997, and responses to it). While these responses reveal a disciplinary audience's immediate sentiments toward a particular text, they are not indicative of the more general impact that the text's contents may have on a scholarly community over time. That is, these initial reactions tell us very little of how the acceptance or rejection of the text's propositions change diachronically. For example, Firth and Wagner's SLA-focused article (1997) initially incited controversy and "angered" several SLA scholars (Gass, Lee, \& Roots, 2007). Their article, however, has over time "crystalized the essence of many of these polemical cognitive-social arguments and provided valuable insights into the perspectives underlying current avenues of SLA research" (Lafford, 2007, p. 744). Thus, Paul, Charney, and Kendall (2001) argue that in order to understand the impact of an academic text on a disciplinary community, we need to observe "[its] acceptance and rejection over time" (p. 374).

Reception studies, as Swales (2012) posits, are retrospective in nature. Such investigations analyze the historical trajectory of audience responses to a text postpublication, primarily through examination of citations and evaluative reactions toward the cited text. While such studies are common in the field of the rhetoric of science (e.g., Harris, 2005; Paul et al., 2001), retrospective analyses of audience reception of texts in TESOL and applied linguistics are a recent phenomenon, comprising to date only the work of Swales (2012; Swales \& Leeder, 2012). Swales examined the reception histories of Hyon's (1996) widely cited review article since its publication (Swales, 2012), and the 15 most cited research articles (RAs) in the journal English for Specific Purposes (ESP) between 1990 and 1999 (Swales \& Leeder, 2012). In both studies, Swales traces who cited the articles, when, where, and how, and suggests possible reasons for why the articles were cited. Similar to Paul et al. (2001), Swales (2012) found that citational uptake is incremental and various factors affect an article's success. He contends that "Hyon (1996) has succeeded essentially because of its value as a review paper" (p. 112), as such reviews bring order 
to the research literature and suggest a way forward (Myers, 1991). Swales and Leeder (2012) report that factors affecting the citational success of the most cited RAs published in ESP include topic, methodology, novelty, and "the right time and place" phenomenon (p. 145). Both studies (Swales, 2012; Swales \& Leeder, 2012) serve to increase the field's awareness of the impact of groundbreaking articles in ways that are more empirical than by intuition alone, highlighting their specific achievements over time. Building on Swales (2012), the present study traces the reception history of F\&J's article since its publication to provide insight into the extent to which and the ways in which this article has impacted SLTE.

\section{Method}

Following Swales (2012), our guides for locating relevant sources were the Google Scholar and Web of Science databases between 1998 and 2014. The Google Scholar search revealed that F\&J's article has been cited 750 times between 1998 and 2014. The Web of Science search returned only 141 citing articles. As Swales (2012) notes, Web of Science primarily includes peerreviewed journal articles, and tends to exclude dissertations, theses, book chapters, books, and other (non-English-language) publications. Therefore, to capture a broader perspective of the extent of F\&J's impact, we examined all peer-reviewed journal articles, books, book chapters in edited volumes, master's theses, and $\mathrm{PhD}$ dissertations identified in Google Scholar. This survey revealed that many were inaccessible (particularly non-English-language texts). We also found that Google Scholar sometimes duplicated citations due to bibliographic information errors (e.g., entering the wrong year). Furthermore, upon examining the texts in the database, we noticed that some publications included F\&J among the references but did not actually cite the article in the texts. Lastly, several citing publications were self-citations by Freeman and/or Johnson either with or without collaborators. All of these texts were omitted from the final analysis.

The final data set consisted of 413 journal articles, books, book chapters, theses, and dissertations. Table 1 depicts the number of texts within each genre that cited F\&J between 1998 and 2014 in Google Scholar. As Table 1 shows, more than $92 \%$ of citations of F\&J occur in peer-reviewed journal articles, dissertations, and book chapters, while books and master's theses cite F\&J less frequently.

We approached our data analysis from various perspectives. We first analyzed the distribution of citations of F\&J over time in each genre and where it was cited. We also examined the publication type (i.e., empirical, theoretical, practice-oriented, review), academic/professional field (e.g., TESOL, foreign language, applied language studies ${ }^{1}$ ), language orientation (i.e., L1 or L2 focus), and focal country (e.g., Canada, Iran, US) in which F\&J's article was cited. We then used Hyland's $(1999,2004)$ citation categories and 
Coffin's (2009) stance framework to analyze citation types and evaluative positions that the citing authors took toward F\&J's proposed reconceptualization. Hyland $(1999,2004)$ classifies citations into four main categories: direct quotation, block quotation (direct quotations of 40 or more words in length), summary, and generalization. Summaries are paraphrases in which, for example, only F\&J are referred to, while generalizations refer to a more inclusive synthesis of F\&J's work and other sources. We followed Hyland's categorization system to determine the ways in which, and the degree to which, F\&J's words, viewpoints, and ideas have been integrated within the theoretical and empirical research of the larger SLTE community.

Table 1

Number of Texts Citing F\&J per Genre

\begin{tabular}{lcr}
\hline Genre & Number of cites in Google Scholar & $\%$ \\
\hline Journal article & 229 & 55.45 \\
Book & 13 & 3.15 \\
Book chapter & 48 & 11.62 \\
Thesis & 18 & 4.36 \\
Dissertation & 105 & 25.42 \\
Total & 413 & 100.00 \\
\hline
\end{tabular}

To analyze how citing authors have evaluated F\&J's propositions, we used Coffin's (2009) stance framework, which is based on systemic-functional linguistics, specifically appraisal theory (Martin \& White, 2005; White, 2003). Drawing on appraisal theory's engagement system, and in particular the attribute subsystem, Coffin's (2009) engagement framework focuses on linguistic expressions writers use "to engage with and negotiate voices and viewpoints" (p. 169). This perspective underscores the dialogic function of language resources to expand or contract dialogic spaces (White, 2003). Coffin's framework consists of three dimensions: writer stance, textual integration, and nature of source. However, due to our interest in understanding F\&J's impact in terms of citing authors' positions toward F\&J's propositions, and how they have changed over time, we only analyzed the citing sources in terms of writer stance, or a writer's affective position toward "the words, observations, viewpoints, and theories that comprise the referenced source" (Coffin, 2009, p. 170). Unlike previous studies (e.g., Hyland, 1999) that restrict analysis to reporting verbs (e.g., contend, emphasize), Coffin's framework includes a broader range of reporting structures including reporting verbs, "evaluative formulations" (e.g., X convincingly argue ...), "stance nouns" (e.g., X's claim that ...) (Jiang \& Hyland, 2015), and contextual and cotextual cues (e.g., ... lends powerful support to X's position ...) to establish evaluative stance. 
Coffin's analytical framework consists of four stance types: acknowledge, distance, endorse, and contest. Acknowledge refers to a neutral stance a writer takes in which no evaluation is offered on the cited work:

(1) Acknowledge: In a 1998 survey article, Freeman and Johnson looked at how the knowledge base of teachers is shaped ... (Journal Article, $2002)^{2}$

Distance differs from acknowledge in that the writer creates a certain detachment from the cited work, thus accepting no responsibility for the reliability of the words, observations, or viewpoints:

(2) Distance: Freeman and Johnson (1998) and Schulz (2002) claim that research on foreign language teacher education is lagging a decade behind ... (Dissertation, 2005)

These two stance features "open up the dialogic space for alternative views" (Coffin, 2009, p. 170), as they represent the cited proposition as one perspective among multiple voices. In contrast, the remaining two stance elements, endorse and contest, commit the writer to a specific viewpoint; they contract the dialogic space because "the writer's personal investment in a viewpoint increases the interpersonal cost of advancing an alternative" (p. 172). Endorse expresses a writer's stance by directly supporting or agreeing with the cited proposition (3) whereas contest is a stance type that directly rejects or criticizes the cited source (4).

(3) Endorse: This research has also validated earlier arguments (Freeman \& Johnson, 1998) that have called for a more robust emphasis on how language teachers develop pedagogical representations of content knowledge ... (Book Chapter, 2014)

(4) Contest: As important and insightful as I find the work associated with the quiet revolution in language teacher education (e.g., Freeman \& Johnson, 1998; Woods, 1996; Richards \& Nunan, 1990; Wallace, 1991), it often fails to make a clear link between its reconceptualization and the workings of ordinary language teacher education programs ... (Journal Article, 2004)

The citations were subsequently categorized as either integral or nonintegral. Swales (1990) explains that integral citations include the cited author(s) as part of the citing sentence, thus placing greater prominence on the cited author(s) (see 1-2 above). Conversely, nonintegral citations refer to parenthetical or superscript numbered citations, which give greater emphasis to the reported message (see 3-4 above). Citation integration can have a crucial rhetorical effect by either expanding or contracting the dialogic space (Coffin, 2009). A referenced proposition that is paraphrased and presented in nonintegral form, for instance, "is more likely to be perceived as an established fact, 
thus creating dialogic contraction" (Coffin, 2009, p. 174). In contrast, direct quotations, especially in integral form, "make a proposition more open to counter argument by being clearly located as the view of but a single source," resulting in dialogic expansion (p. 174).

Each instance of F\&J citation was analyzed manually to identify citation distribution, publication type, field, language orientation, text section, citation category, and stance type. The first author examined journal articles, the second author analyzed books and book chapters, and the third author focused on theses and dissertations. To establish intercoder agreement, each author checked $25 \%$ of randomly selected citation instances from the data sets of the other two authors. Agreement between the authors was nearly $99 \%$ for journal articles, theses, and dissertations, and $94.7 \%$ for books and book chapters. The discrepancies were discussed until all three authors reached full agreement.

\section{Results and Discussion}

This section presents the reception history of F\&J in the field of SLTE. After reporting on the citation analytics of F\&J over the 16-year period, we set forth the citational presentation and integration of F\&J in citing sources. We then focus on citation types and evaluative stances that citing authors have taken toward F\&J's proposals. Finally, we examine the propositional content from F\&J's article that authors have integrated into their own texts.

\section{Citation Analytics}

Since 1998, F\&J's contribution has achieved notable recognition by the academic community. Table 2 shows the frequency of citing texts per 4-year period for each genre examined. F\&J's contribution may be described as having experienced marked surges in interest during Periods 2 (2003-2006) and 4 (2011-2014), with the overall number of citing texts having more than tripled between the first and second periods, and having nearly doubled from Period 3 to Period 4 for journal articles. While the number of citations of F\&J in books, book chapters, and theses has progressed nonlinearly over time, journal articles and dissertations citing F\&J have increased in a linear fashion diachronically. As Table 2 shows, most citations derive from texts published in Period 4 (2011-2014), and, perhaps predictably, the fewest citations occur in Period 1 (1999-2002). This indicates that F\&J's article had a slow start in gaining the SLTE community's attention, which is to be expected, given the time needed for readers to become aware of new publications. However, it has since gained increasing recognition over time.

Subsequent examination of the journals in which F\&J's article has been cited and the global contexts on which these citing authors have focused offers greater insight into the specific areas of the academic community that draw on F\&J's work. F\&J's paper has been cited in articles that appear in 132 
journals focusing on general education, L2 teaching and learning, applied language studies, SLA, general humanities and social sciences, and even science and engineering. It is not surprising, as Table 3 demonstrates, that 8 of the top 10 journals listed are related to language learning and teaching or applied language studies; more than $32 \%$ of the citing articles appear in these 8 journals. The breadth of journals in which F\&J appears highlights its widespread impact on both L2 and general education.

Table 2

Citing Texts per 4-Year Period

\begin{tabular}{lccccccc}
\hline & $\begin{array}{c}\text { No. of cites } \\
\text { in Google } \\
\text { Scholar }\end{array}$ & $\begin{array}{c}\text { Journal } \\
\text { article }\end{array}$ & Book & $\begin{array}{c}\text { Book } \\
\text { chapter }\end{array}$ & Thesis & Dissertation & $\%$ \\
\hline 1. 1999-2002 & 29 & 21 & 3 & 2 & 1 & 2 & 7.02 \\
2. 2003-2006 & 84 & 50 & 1 & 15 & 3 & 15 & 20.34 \\
3. 2007-2010 & 115 & 55 & 3 & 12 & 8 & 37 & 27.85 \\
4. 2011-2014 & 185 & 103 & 6 & 19 & 6 & 51 & 44.79 \\
Total & 413 & 229 & 13 & 48 & 18 & 105 & 100.00 \\
\hline
\end{tabular}

Note. No publication cited F\&J in 1998.

Table 3

Top Ten Citing Journals in Google Scholar

\begin{tabular}{lcr}
\hline Journal & Number of cites in Google Scholar & $\%$ \\
\hline 1. TESOL Quarterly & 24 & 9.96 \\
2. Modern Language Journal & 14 & 5.81 \\
3. System & 9 & 3.73 \\
4. TESL Canada Journal & 8 & 3.32 \\
5. TESL-EJ & 6 & 2.49 \\
6. Language Teaching & 6 & 2.49 \\
7. Foreign Language Annals & 6 & 2.49 \\
8. Teachers and Teaching & 6 & 2.49 \\
9. Language Teaching Research & 5 & 2.07 \\
10. Teaching and Teacher Education & 4 & 1.66 \\
\hline
\end{tabular}

Further examination of the academic/professional field, language orientation, and focal country of the citing texts provided a more specific overview of the themes typically linked to F\&J's contribution. Naturally, this analysis revealed that the vast majority (more than $81 \%$ ) of all citing texts focus on 
TESOL-related issues in English as a second/foreign language (ESL/EFL) contexts, and nearly $14 \%$ related to the field of the teaching and learning of other foreign languages (e.g., Spanish, German, Chinese). Only 2.7\% of texts are specifically in the domain of general education, and the few remaining texts address matters in the fields of applied language studies and SLA. Of those in the domain of TESOL, more than 50\% are situated in EFL settings with the others in various ESL milieus. Although nearly two-thirds are concentrated in seven EFL countries (Brazil, China, Iran, Japan, Korea, Taiwan, and Turkey), 38 EFL contexts in total are represented. This may be indicative of the global impact F\&J's work has had on the study of L2 teaching and teachers in a plurality of TESOL situations.

F\&J's paper has been cited widely in empirical, review, theory-oriented, and practice-oriented texts. As Table 4 indicates, nearly three-quarters of citing texts were research reports (RRs) while only a few published state-ofthe-art or literature reviews (LRs) have cited F\&J. This may be due to the infrequency in which LRs are generally published. Somewhat surprisingly, however, the fewest citing texts are practice-oriented papers (PPs). One interpretation is that F\&J's proposals have had a limited impact on actual SLTE practices, or more likely, PPs are less commonly published in the text types we examined but may occur more frequently in other publication types (e.g., professional newsletters and magazines). While theory-oriented papers (TPs) were more common in book chapters than RRs, it is important to note that the SLTE community overall has embraced F\&J's call for "grounded examinations of language teaching within the broader framework of teacher-learner, contexts of schools and schooling, and the pedagogical process" (p. 413), as most citing texts are RRs (more than $72 \%$ ).

Table 4

Text Types per Genre

\begin{tabular}{lccccccr}
\hline Type & Total & $\begin{array}{c}\text { Journal } \\
\text { article }\end{array}$ & Book & $\begin{array}{c}\text { Book } \\
\text { chapter }\end{array}$ & Thesis & Dissertation & $\%$ \\
\hline RR & 299 & 155 & 6 & 15 & 18 & 105 & 72.40 \\
LR & 28 & 26 & 0 & 2 & 0 & 0 & 6.78 \\
TP & 67 & 35 & 6 & 26 & 0 & 0 & 16.22 \\
PP & 19 & 13 & 1 & 5 & 0 & 0 & 4.60 \\
Total & 413 & 229 & 13 & 48 & 18 & 105 & 100.00 \\
\hline
\end{tabular}

Note. $\mathrm{RR}=$ research report; $\mathrm{LR}=$ literature review; $\mathrm{TP}=$ theory-oriented paper; $\mathrm{PP}=$ practiceoriented paper.

\section{Citational Presentation and Integration}

Similar to Hyland's (1999) findings of citation practices of RAs across disciplines, the vast majority of citations were expressed as paraphrases, either as 
summary or generalization (Table 5). According to Hyland, summary and generalization are "the most effective ways of achieving [a writer's argument] as they allow the writer greater flexibility to emphasize and interpret what they are citing" (p. 348). Interestingly, unlike Hyland's finding of humanities and social science RAs - and specifically applied linguistics - in which only $10 \%$ of citations were direct or block quotations, F\&J's exact words have been frequently quoted by citing authors $(\sim 23 \%)$. Furthermore, contrasting Swales's (2012) study of Hyon's (1996) article, in which he found no block quotes and only a limited number of direct quotes, in the present study nearly a quarter of all citations incorporated F\&J's exact words to varying degrees. Hyland (1999) states that writers tend to use the exact words of source texts only "when writers consider them to be the most vivid and effective way of presenting their case" (p. 348). Although most F\&J citations are presented as summary or generalization, it is clear that many citing authors found F\&J's specific wording effective in presenting and supporting their own argumentation.

Table 5

Citational Presentation of F\&J per Genre

\begin{tabular}{lrcccccc}
\hline Category & Total & $\begin{array}{c}\text { Journal } \\
\text { article }\end{array}$ & Book & $\begin{array}{c}\text { Book } \\
\text { chapter }\end{array}$ & Thesis & Dissertation & $\%$ \\
\hline BQ & 48 & 21 & 4 & 9 & 3 & 11 & 4.33 \\
DQ & 204 & 90 & 5 & 26 & 12 & 71 & 18.41 \\
SS & 469 & 203 & 8 & 78 & 20 & 160 & 42.33 \\
GG & 387 & 168 & 15 & 21 & 29 & 154 & 34.93 \\
Total & 1,108 & 482 & 32 & 134 & 64 & 396 & 100.00 \\
\hline
\end{tabular}

Note. $\mathrm{BQ}=$ block quotation; $\mathrm{DQ}=$ direct quotation; $\mathrm{SS}=$ summary; $\mathrm{GG}=$ generalization.

The analysis of the block and direct quotes provided insight into what the academic community considers to be the most memorable quotes. The three most commonly cited quotes, in part or in full, are listed below. The first quote (5) was cited 37 times, the second quote (6) 24 times, and the third quote (7) 12 times.

(5) Drawing on work in general education, teacher educators have come to recognize that teachers are not empty vessels waiting to be filled with theoretical and pedagogical skills; they are individuals who enter teacher education programs with prior experiences, personal values, and beliefs that inform their knowledge about teaching and shape what they do in their classrooms. (F\&J, p. 401)

(6) We argue that the core of the new knowledge-base must focus on the activity of teaching itself; it should center on the teacher who does it, 
the contexts in which it is done, and the pedagogy by which it is done. (F\&J, p. 397)

(7) Thus we argue that, for the purposes of educating teachers, any theory of SLA, any classroom methodology, or any description of that English language as content must be understood against the backdrop of teachers' professional lives, within the settings where they work, and within the circumstances of that work. (F\&J, p. 405)

These three quotes combined get at the heart of F\&J's article. The first quote highlights the important role that teachers' prior beliefs, knowledge, and experience play in their pedagogical practice. The second focuses on F\&J's actual proposals for the new knowledge base of SLTE, while the third is an extension of what F\&J view as the central concern of SLTE. This strong citational support of F\&J indicates how important the field considers the social context of teaching to be, thus recognizing Freeman and Johnson as the specialists who first introduced these ideas to the SLTE community.

The use of integral versus nonintegral citations further serves to indicate, to a certain extent, how important the academic community considers the issues raised by F\&J to be. As Table 6 shows, citing authors have included F\&J extensively in the structure of the citing sentences in the form of integral citation (nearly $50 \%$ ), thereby placing significance on them as the messengers of the reported message. This finding is particularly interesting in light of the fact that the norm in, for example, applied linguistics RAs is only one-third (Hyland, 1999).

Table 6

F\&J Integration per Genre

\begin{tabular}{lccccccc}
\hline Type & Total & $\begin{array}{c}\text { Journal } \\
\text { article }\end{array}$ & Book & $\begin{array}{c}\text { Book } \\
\text { chapter }\end{array}$ & Thesis & Dissertation & $\%$ \\
\hline Integral & 527 & 223 & 9 & 78 & 21 & 196 & 47.61 \\
Nonintegral & 581 & 259 & 23 & 56 & 43 & 200 & 52.39 \\
Total & 1,109 & 483 & 32 & 135 & 64 & 396 & 100.00 \\
\hline
\end{tabular}

Combining citational presentation with author integration (Table 7) reveals that citing authors preferred overwhelmingly to position F\&J within the sentence grammar (i.e., integral form) for all citation categories except generalization. As mentioned earlier, when quoted material is presented in integral form, propositions are framed as the view of the cited source, thus expanding the dialogic space (Coffin, 2009), as (8) illustrates:

(8) Central to this concept of SLTE is Freeman and Johnson's argument that "language teacher education is primarily concerned with teachers as learners of language teaching ..." (Dissertation, 2007) 
Table 7

Citational Presentation and F\&J Integration per Genre

\begin{tabular}{lrrrcccr}
\hline Category & Total & $\begin{array}{c}\text { Journal } \\
\text { article }\end{array}$ & Book & $\begin{array}{c}\text { Book } \\
\text { chapter }\end{array}$ & Thesis & Dissertation & $\%$ \\
\hline BQ-I & 34 & 19 & 0 & 5 & 2 & 8 & 3.07 \\
BQ-N & 14 & 2 & 4 & 4 & 1 & 3 & 1.26 \\
DQ-I & 130 & 63 & 2 & 14 & 6 & 45 & 11.73 \\
DQ-N & 74 & 27 & 3 & 12 & 6 & 26 & 6.68 \\
SS-I & 342 & 132 & 6 & 55 & 13 & 136 & 30.87 \\
SS-N & 127 & 71 & 2 & 23 & 7 & 24 & 11.46 \\
GG-I & 21 & 9 & 1 & 4 & 0 & 7 & 1.90 \\
GG-N & 366 & 159 & 14 & 17 & 29 & 147 & 33.03 \\
Total & 1,108 & 482 & 32 & 134 & 64 & 396 & 100.00 \\
\hline
\end{tabular}

Note. $\mathrm{BQ}=$ block quote; $\mathrm{DQ}=$ direct quote; $\mathrm{SS}=$ summary; $\mathrm{GG}=$ generalization; I = integral; $\mathrm{N}$ $=$ nonintegral.

In (8), the citing author positions F\&J's exact words as belonging to them, locating F\&J's argument about the nature of SLTE as just one viewpoint among other scholars' perspectives of SLTE. Among paraphrased materials (i.e., summaries and generalizations), as shown in Table 7, there is a combined greater number in the nonintegral form. Thus, when citing authors of F\&J use the nonintegral form, they seem to contract the dialogic space by presenting the propositions as established facts; for example:

(9) The empirical studies and educational theories repeatedly show that teachers' thought[s] direct their classroom practice (Clark \& Peterson, 1986; Fang, 1996; Freeman \& Johnson, 1998) ... (Thesis, 2006)

In (9), the thesis author uses the evaluative formulation repeatedly show to indicate that the subsequent proposition is well established.

It is interesting to note, however, that in the case of summary, F\&J's ideas are mostly presented as integral form:

(10) SLTE, as [F\&J] suggest, is shifting its focus to how one learns to teach ... (Book, 2014)

When only F\&J is included in the propositional sentence, as (10) illustrates, citing authors are more inclined to "foreground and draw attention to [their] engagement with" F\&J (Coffin, 2009, p. 183), despite not directly quoting F\&J's exact words. In fact, besides generalization, F\&J are mostly cited in integral form in the other three citation categories (block quote, direct quote, summary). Adopting a hermeneutic stance for a moment, we see such prominence of F\&J in the sentence grammar of citing authors' prose as signalling 
the notable role F\&J play as the original messengers of the cited words and/ or ideas. However, making F\&J's presence prominent and engaging directly with F\&J is not necessarily indicative of the citing authors' positive stance toward the essence of F\&J's message, as "not all citations within an article are necessarily positive" (Egbert, 2007, p. 158). Therefore, our analysis now turns to writer stance to examine how citing authors have evaluated F\&J's work.

\section{Evaluative Stance}

Analysis of the evaluative stances adopted by the citing authors indicates that a neutral stance is the most dominant. As Table 8 shows, citing authors have primarily adopted a neutral stance in all four periods by merely acknowledging F\&J or even distancing themselves from F\&J's ideas, words, or viewpoints. The effect of taking such stances is "dialogically expansive ... with attributed views being represented via an impartial reporting voice" (Coffin, 2009, p. 180).

Table 8

Writer Stance per 4-Year Period

\begin{tabular}{lrrrrr}
\hline Period & Total & \multicolumn{1}{c}{ ACK (\%) } & \multicolumn{1}{c}{ DIS $(\%)$} & \multicolumn{1}{c}{ END $(\%)$} & CON (\%) \\
\hline $1.1999-2002$ & 88 & $46(52.27)$ & $19(21.59)$ & $23(26.14)$ & $0(0.00)$ \\
2. 2003-2006 & 240 & $140(58.33)$ & $36(15.00)$ & $49(20.42)$ & $15(6.25)$ \\
3. 2007-2010 & 303 & $189(62.38)$ & $37(12.21)$ & $71(23.48)$ & $6(1.98)$ \\
4. 2011-2014 & 477 & $299(62.68)$ & $61(12.79)$ & $112(23.48)$ & $5(1.05)$ \\
Total & 1,108 & $674(60.83)$ & $153(13.81)$ & $255(23.01)$ & $26(2.35)$ \\
\hline
\end{tabular}

Note. ACK = acknowledge; DIS = distance; END = endorse; CON = contest.

Examples below depict how one author acknowledges F\&J's words (11) while another distances herself (12), thus offering a neutral appraisal of F\&J or placing the responsibility of the proposition on F\&J. Distance does not imply that the citing author necessarily agrees or disagrees with the cited proposition, although it could be that the author ultimately agrees with F\&J. Along with acknowledge, distance is dialogically expansive, opening up the dialogic space for other perspectives ${ }^{3}$.

(11) Furthermore, as observed by Freeman and Johnson (1998, p. 398): "The assumptions that have underlain the practice of language teacher education ..." (Dissertation, 2005)

(12) Freeman and Johnson (1998) argue that the knowledge-base of the teachers must include not only disciplinary or subject matter knowledge that defines how languages are structured, used, or acquired, it must also account for the content of L2 teaching ... (Book Chapter, 2005) 
These findings are consistent with Coffin (2009) and Hyland (1999), who also found that most authors in soft disciplines take a noncommittal, as opposed to a strongly positive or negative, position toward cited material. Taking a disinterested position conveys impartiality toward the cited texts, "reflecting the need to build a convincing argument by simply displaying an awareness of prior or parallel research without appearing to corrupt it with personal judgment" (Hyland, 1999, p. 361). Among the dialogically expansive stances, there are considerably more instances of acknowledge than distance. Such a position indicates that citing authors, while taking a noncommittal stance, nevertheless align indirectly with F\&J's position (Coffin, 2009). As discussed above, most RR authors tend to cite F\&J in the introduction and/or literature review. As these sections generally function to create a research space by locating research within the field and reviewing previous literature (Swales, 1990), citing authors of F\&J seem primarily to be displaying their awareness of F\&J and their proposals within the landscape of SLTE rather than exploiting F\&J to carve a research niche in order to justify their current work.

However, citing authors have also frequently taken a strong evaluative position toward F\&J. As shown in Table 8, more than $25 \%$ of citations endorse F\&J in Period 1 (1999-2002) - the period of theoretical innovation - with no authors initially contesting them, as (13) and (14) illustrate:

(13) We heartily endorse Freeman and Johnson's (1998) call for more research ... (Journal Article, 2000)

(14) The field is realizing that ... we must inquire into their cognitive worlds and personal teaching practices (Freeman \& Johnson, 1998 ... [)] (Journal Article, 2002)

The positive evaluation of F\&J, however, decreases in Period 2 (2003-2006) the period of contestation - with several authors questioning, rejecting, and criticizing F\&J's proposals, as illustrated in (15) and (16):

(15) We would like to add to the discussion by questioning the extent to which the profession should be reconceptualized along the lines suggested by Freeman and Johnson. (Journal Article, 2003)

(16) We worry that Freeman and Johnson (1998) may risk appearing to fall into the noninterface fallacy ... (Book Chapter, 2005)

This contestation period is then followed by periods of increasing community acceptance. As shown in Table 8, the contest stance decreases in the third (2007-2010) and fourth (2011-2014) periods, while the number of authors positively evaluating F\&J in the same periods increases. In fact, only 8 of the 307 authors who have cited F\&J in those two periods offer any form of negative criticism.

Examining the experience of citing authors sheds further light on the evaluative stances taken regarding F\&J's work. Of the 105 doctoral and 18 
master's student writers in the data, only 4 directly challenge F\&J, which supports Coffin's (2009) finding that one doctoral student did not take this stance in her dissertation. One explanation might be that the more established writers of journal articles bring a more critical perspective to their own writing than do less experienced doctoral students, resulting in the substantial amount of the acknowledge stance throughout student writing. However, as Hyland (1999) found, the majority of RA writers also take a more neutral stance toward cited material. Coffin (2009) explains that the heavy use of the acknowledge stance contributes indirectly to authors' supporting their own positions in relation to cited material, in this case F\&J. It might be the case that as scholarly works, such as F\&J, become more established within an academic community, authors of journal articles seek out aspects of those works that align with their own perspective as a form of intellectual allegiance or deference. As the contest stance has decreased over time, the number of authors who distance themselves from F\&J's words, ideas, and viewpoints has also declined.

Based on this analysis, a few trending patterns in the impact of F\&J's contribution to the field of SLTE are apparent. First, among the dialogically expansive categories, acknowledge has increased while distance has decreased over time. This may indicate that, by taking a more neutral position toward F\&J's viewpoints rather than taking no responsibility for their reliability, citing authors have been "drawing out aspects of [F\&J] that indirectly support [their] position" (Coffin, 2009, p. 182). They have thus been subtly aligning with F\&J's viewpoints in their writing. Furthermore, among the dialogically contractive stances, endorse has increased while contest has decreased over time. This diachronic change in attitude suggests that citing authors have increasingly been supporting and agreeing with the proposals outlined in F\&J's article. Collectively, our analysis reveals that citing authors have opened up the dialogic space more than they have closed it. However, when citing authors contract this space, they have been much more inclined to take a favourable position toward F\&J. The positive reception and greater acceptance of F\&J's "quiet revolution" in SLTE (Johnson, 2000) point to their proposals becoming more widely recognized in SLTE over time.

\section{Propositional Content}

Lastly, among the propositional content discussed in F\&J's article and integrated into citing texts, five central themes emerge: (a) the core of the new knowledge base (28.2\%); (b) a social constructivist view of teacher knowledge and learning (23.3\%); (c) criticism of traditional SLTE knowledge base and

programs (13.5\%); (d) the impact of teachers' prior experience, beliefs, and values on knowledge and practices (12\%); and (e) a review of SLTE (8.6\%). Unsurprisingly, the most cited content is the core of the new knowledge base; for example, one dissertation stated: 
(17) In their own words: "The core of the new knowledge-base must focus on the activity of teaching itself ..." (Dissertation, 2014)

The second most commonly cited material has been F\&J's contention that teacher knowledge and teacher learning can best be approached from a social constructivist perspective in which knowledge and learning are socially negotiated and constructed in situated contexts:

(18) It is now more than ten years since constructivism arrived in teacher education, "shifting the conception of teaching from a behavioral view of what people do when they teach languages to a constructivist view of how people learn to teach" (Freeman \& Johnson, 1998: 402) (Journal Article, 2011)

In building up toward outlining their proposals for the new knowledge base, F\&J first leveled several criticisms against the traditional approach to SLTE, which have been taken up by many citing authors to support their own positions:

(19) The discrepancy between theory and practice perceived by teachers in the field has frequently been reported as a limitation of traditional language teacher education programs (Freeman \& Johnson, 1998). (Book Chapter, 2013)

Another important point F\&J raised was the critical role that teachers' prior experience, knowledge, and values play in shaping their pedagogical views and practices:

(20) Freeman and Johnson (1998) asserted that "teachers are not empty vessels waiting to be filled with theoretical and pedagogical skills; they are individuals ... with prior experiences, personal values, and beliefs that inform their knowledge about teaching and shape what they do in their classrooms" (p. 401). (Thesis, 2006)

Lastly, citing authors valued F\&J's paper for its abbreviated review of the then state of the art of SLTE, prior to the publication of their paper:

(21) A very important contribution made by Freeman and Johnson (1998) has been to point to the large amount of research that has been done on teacher learning in general. (Book Chapter, 2005)

Themes emerging from the analysis of the content selected by citing authors cover the range of issues expressed and proposals offered in F\&J's article, including the importance of recognizing teachers' prior knowledge, beliefs, and practices; the need to view learning-to-teach from a social constructivist perspective; and locating the core of the knowledge base on "[w] ho teaches what to whom, where?" (Freeman \& Johnson, 1998, p. 405). In effect, it could be argued that F\&J's principal legacy may lie in (a) stirring the 
pot in the debate over what constitutes the knowledge base of SLTE; (b) offering a socially situated framework that begins with the activity of teaching itself - the person, place, and manner; and (c) launching a research program focused on the process of language teaching itself and the teachers who do it, as evidenced by the overwhelming number of citing texts.

\section{Conclusion}

The results of this reception study of F\&J's (1998) paper indicate that the article not only has been accumulating greater citational attention over time, but it has also gained greater acceptance diachronically. In the introductory paragraph of their paper, F\&J lamented that "teacher education has been much done but relatively little studied in the field" (p. 398). However, the analysis reveals that the majority of texts citing F\&J are empirical in nature in various L2 teaching and learning circumstances, thus indicating that the SLTE community has taken up F\&J's call for greater research on understanding L2 teaching and teachers in order to "provide the foundation of language teacher education in TESOL" (p. 413). Furthermore, although there are slightly more parenthetical citations and a significant amount of paraphrasing, nearly half of the citations are integral, with an abundant number of direct and block quotations. Most citations are neutral, but the number of authors supporting or endorsing F\&J has been strong, with decreasing opposition over time. Most are within the domain of English language teaching and the teaching of other L2s, with a few in general education. If we probe more closely into the propositional aspects taken up by citing authors, we see that F\&J's paper is not only frequently quoted for its memorably worded themes, but the content cited also covers the full spectrum of propositions discussed in the paper. Taken together, while F\&J's reconceptualization paper sparked some initial controversy, its proposals have gained wider acceptance and have edged closer to the center of SLTE over time.

The SLTE community's strong endorsement of F\&J's work further highlights it as a foundational article for the professional practice of language teaching. An understanding of F\&J's contributions, particularly the key principles that our study has identified as most prominently promoted by the community, needs to underlie effective teaching practices. Knowing that teachers" "prior experiences, personal values, and beliefs ... inform their knowledge about teaching and shape what they do in their classroom" (F\&J, p. 401) is not simply a message directed at teacher educators but has equal importance for language teachers as well, whether such teachers are situated in more traditional ESL (e.g., Canada, UK, US) or EFL (e.g., Brazil, China, Turkey) milieus.

By tracking the citational uptake of F\&J's article since its publication, we provided empirical evidence that signals the successful impact of F\&J's connection with the relatively young field of SLTE. Although we approached 
the analysis from various perspectives, we admit that a few limitations exist in our analysis. For example, there is no established methodology for determining the impact of academic texts (Harris, 2005) aside from bibliometric citation data (e.g., Web of Science or Google Scholar citations), which tell us little in the way of how a text is received by the academic community. Future research examining the reception of other landmark publications in TESOL/applied linguistics or other fields of study could consider utilizing ethnographic methods, such as interviews, to complement the analytical approaches employed in the current study. Researchers could interview well-established members of the community, particularly those who have been involved in the field during the publication of a landmark paper, and perhaps the cited author(s), to gain their perspectives on the nature of how and why the paper has been received in the discipline. Furthermore, researchers could combine the analysis with corpus-based techniques to examine the most frequently occurring evaluative expressions in relation to the cited work and how the appraisal of the text has changed diachronically. Doing so would further triangulate the evidence and provide a more robust multidimensional analysis of the impact of a particular text over time (Paul et al., 2001). Comparable studies may also be designed to document the impact trajectory of other possibly important contributions (e.g., Kumaravadivelu, 1994; Nunan, 1991; Prabhu, 1990) to the continuing history of TESOL/applied linguistics. Such studies may illuminate the degree to which these landmark articles have had similar or different reception trajectories over time.

Finally, reception studies of landmark publications, especially in younger fields such as TESOL/applied linguistics, "can make practitioners ... more aware of the past efforts and previous achievements" of the field, and "provide one kind of valuable bridge between past and present" (Swales \& Leeder, 2012, p. 145). Such studies can provide a historical perspective for newer members of the community to gain better insights into how the field and its current knowledge, theories, and practices have developed over time. The current reception achieves this goal by tracing diachronically the "who, what, when, where, how, and why" of F\&J's landmark article in the field. However, we can only speculate as to how the uptake and impact of F\&J might continue or change in a different direction over the next 16 years.

\section{Notes}

1 While applied language studies generally comprise language learning and teaching issues, we included in this category those articles that are concerned only with theoretical or methodological considerations or research in applied language studies not directly related to teaching or learning.

2 For each illustration presented from our data set, we include the genre and year in which the excerpt appears; for example, (Journal Article, 2002) denotes that the excerpt was extracted from a journal article published in 2002. 
3 Note that in Coffin's (2009) framework, had the citing author in (12) used some kind of evaluation formulation along with the reporting verb, such as argue persuasively or convincingly argue, this would be categorized as an endorse stance in which this author indicates support for, or agreement with, F\&J, and thus representing F\&J's proposition as authoritative or convincing.

\section{Acknowledgements}

We would like to thank the University of Wollongong for providing funding for a research assistant, Michael Burri, to collect a portion of the data used in this study, and the three anonymous reviewers for their constructive feedback.

\section{The Authors}

Joseph J. Lee, $\mathrm{PhD}$, is the Assistant Director of the English Language Improvement Program (ELIP) in the Department of Linguistics at Ohio University. His research and teaching interests include English for Specific Purposes, genre studies, classroom discourse, advanced academic literacy, applied corpus linguistics, and second language teacher education.

John Murphy is Professor of Applied Linguistics at Georgia State University, Atlanta. His recent publications include Teaching Pronunciation (TESOL, 2013), Teaching the Pronunciation of English: Focus on Whole Courses (University of Michigan Press, 2017), and "Intelligible, Comprehensible, Nonnative Models in ESL/EFL Pronunciation Teaching" (System, 2014).

Amanda Baker, $\mathrm{PhD}$, is Coordinator of the TESOL program at the University of Wollongong in Australia. Her research interests focus on the dynamic relationships that exist between second language teachers' knowledge, beliefs, and practices, especially in the areas of L2 pronunciation, speaking, and listening pedagogy. Her publications include articles in TESOL Quarterly, Pragmatics $\mathcal{E}$ Cognition, and TESOL Journal in addition to several book chapters.

\section{References}

Coffin, C. (2009). Incorporating and evaluating voices in a film studies thesis. Writing $\mathcal{E}$ Pedagogy, 1(2), 163-193. doi:10.1558/wap.v1i2.163

Egbert, J. (2007). Quality analysis of journals in TESOL and applied linguistics. TESOL Quarterly, 41(1), 157-171. doi:10.1002/j.1545-7249.2007.tb00044.x

Faez, F. (2011). Developing the knowledge base of ESL and FSL teachers for K-12 programs in Canada. Canadian Journal of Applied Linguistics, 14(1), 29-49.

Firth, A., \& Wagner, J. (1997). On discourse, communication, and (some) fundamental concepts in SLA research. Modern Language Journal, 81(3), 285-300. doi:10.1111/j.1540-4781.1997.tb05480.x

Fleming, D., Bangou, F., \& Fellus, O. (2012). ESL teacher-candidates' beliefs about language. TESL Canada Journal, 29(1), 39-56. http://dx.doi.org/10.18806/tesl.v29i1.1088

Freeman, D., \& Johnson, K. E. (1998). Reconceptualizing the knowledge-base of language teacher education. TESOL Quarterly, 32(3), 397-417. doi:10.2307/3588114

Freeman, D., \& Johnson, K. E. (2004). Comments on Robert Yates and Dennis Muchisky's “On reconceptualizing teacher education." Readers react ... Common misconceptions about the quiet revolution. TESOL Quarterly, 38, 119-127. doi:10.2307/3588261

Freeman, D., \& Johnson, K. E. (2005). Response to Tarone and Allwright. In D. J. Tedick (Ed.), Second language teacher education: International perspectives on research and practice (pp. 25-32). Mahwah, NJ: Lawrence Erlbaum Associates.

Gass, S., Lee, J., \& Roots, R. (2007). Firth and Wagner (1997): New ideas or a new articulation? Modern Language Journal, 91, 788-799. doi:10.1111/j.1540-4781.2007.00669.x

Harris, R. A. (2005). Reception studies in the rhetoric of science. Technical Communication Quarterly, 14(3), 249-255. doi:10.1207/s15427625tcq1403_2 
Hyland, K. (1999). Academic attribution: Citation and the construction of disciplinary knowledge. Applied Linguistics, 20(3), 341-367.

Hyland, K. (2004). Disciplinary discourses. Ann Arbor, MI: University of Michigan Press.

Hyon, S. (1996). Genre in three traditions: Implications for ESL. TESOL Quarterly, 30(4), 693-722. doi: $10.2307 / 3587930$

Jiang, F., \& Hyland, K. (2015). 'The fact that': Stance nouns in disciplinary writing. Discourse Studies, 17, 529-550. doi:10.1177/1461445615590719

Johnson, K. E. (2000). Innovations in TESOL teacher education: A quiet revolution. In K. E. Johnson (Ed.), Teacher education (pp. 1-7). Alexandria, VA: TESOL.

Kumaravadivelu, B. (1994). The postmethod condition: (E)merging strategies for second/foreign language teaching. TESOL Quarterly, 28(1), 27-48. doi:10.2307/3587197

Lafford, B. A. (2007). Second language acquisition reconceptualized? The impact of Firth and Wagner (1997). Modern Language Journal, 91, 735-756. doi:10.1111/j.1540-4781.2007.00666.x

Martin, J. R., \& White, P. R. R. (2005). The language of evaluation. Basingstoke, UK: Palgrave Macmillan.

Muchisky, D., \& Yates, R. (2004). The authors respond...Defending the discipline, field, and profession. TESOL Quarterly, 38(1), 134-140. doi:10.2307/3588263

Myers, G. (1991). Stories and styles in two molecular biology review articles. In C. Bazerman \& J. Paradis (Eds.), Textual dynamics of the profession (pp. 45-75). Madison, WI: University of Wisconsin Press.

Nunan, D. (1991). Communicative tasks and the language curriculum. TESOL Quarterly, 25(2), 279-295. doi:10.2307/3587464

Paul, D., Charney, D., \& Kendall, A. (2001). Moving beyond the moment: Reception studies in the rhetoric of science. Journal of Business and Technical Communication, 15(3), 372-399. doi:10.1177/105065190101500305

Prabhu, N. S. (1990). There is no best method-Why? TESOL Quarterly, 24(2), 161-176. doi:10.2307/3586897

Salas, S. (2007). Gatekeeping, advocacy, and other dilemmas of teaching ESL learning support in a public two-year college in north Georgia (Unpublished doctoral dissertation). University of Georgia, Athens, GA.

Swales, J. (1990). Genre analysis. Cambridge, UK: Cambridge University Press.

Swales, J. (2012). A text and its commentaries: Toward a reception history of "Genre in three traditions" (Hyon, 1996). Ibérica, 24, 103-116.

Swales, J., \& Leeder, L. (2012). A reception study of the articles published in English for Specific Purposes from 1990-1999. English for Specific Purposes, 31(2), 137-146. doi:10.1016/j. esp.2011.07.003

Tarone, E., \& Allwright, D. (2005). Language teacher-learning and student language-learning: Shaping the knowledge base. In D. J. Tedick (Ed.), Second Language Teacher Education: International Perspectives (pp. 5-23). Mahwah, NJ: Lawrence Erlbaum Publishers.

Vélez-Rendón, G. (2002), Second language teacher education: A review of the literature. Foreign Language Annals, 35(4), 457-467.

White, P. R. R. (2003). Beyond modality and hedging: A dialogic view of the language of intersubjective stance. Text - Interdisciplinary Journal for the Study of Discourse, 23(2), 259-284.

Wright, T. (2010). Second language teacher education: Review of recent research on practice. Language Teaching, 43(3), 259-296. doi:10.1017/S0261444810000030

Yates, R., \& Muchisky, D. (2003). On reconceptualizing teacher education. TESOL Quarterly, 37(1), 135-147. doi:10.2307/3588468 